\title{
Heavy Ion Testing of Commercial GaN Transistors in the Radio Frequency Spectrum
}

\author{
Sarah E. Armstrong, Member, IEEE, Ken Bole, Holly Bradley, Ethan Johnson, \\ James Staggs, Member, IEEE, Walter Shedd, Patrick L. Cole, Casey H. Rice, J. David Ingalls, \\ Casey C. Hedge, Adam R. Duncan and Brian D. Olson
}

\begin{abstract}
Commercial gallium nitride (GaN) high-electron mobility transistors (HEMTs) are tested in the radio frequency (RF) spectrum at heavy ion facilities to explore space environment stresses on these emerging technologies. Findings indicate that gate leakage degradation is a key parameter to consider when selecting devices. Variations in the manufacturing process may drive product selection for use in harsh environments.
\end{abstract}

\section{INTRODUCTION}

$\mathrm{R}$ ECENT interest in gallium nitride $(\mathrm{GaN})$ devices for radiation environments has prompted consideration for use in space systems [1] and [2]. The majority of the studies, however, focus on direct current (DC) measurements with limited RF testing being reported. Efforts to explore the DC and $\mathrm{RF}$ response in a radiation environment as a baseline characterization for space-based applications are underway. The focus of the experiments is to first, characterize the RF response and second, characterize the gate and drain current degradations seen in [3] and [4]. Data relating to this effort are presented in this paper.

The devices tested are all high-electron mobility transistors (HEMTs). A sample GaN HEMT device structure is shown in figure 1. These are majority carrier devices with a thin AlGaN layer for electron generation. Table 1 shows the rated power, test conditions, and test facility of the tested devices.

\section{EXPERIMENTAL DETAILS}

The devices were tested at one of two heavy ion facilities, Lawrence Berkeley National Laboratory or Texas A\&M University's cyclotron. This section describes the test setups for each facility and the equipment used.

Manuscript received July 12, 2015. This work was supported in part by NSWC Crane's Naval Innovation in Science and Engineering (NISE) funding.

S. E. Armstrong, P. L. Cole, C. H. Rice, J. D. Ingalls, C.C. Hedge, A. R. Duncan, and B. D. Olson are with the Naval Surface Warfare Center, Crane Division, in Crane, IN 47522 USA (telephone: 812-854-3779, email: sarah.armstrong@navy.mil).

K. Bole, E. Johnson, J. Staggs, and W. Shedd are with Air Force Research Laboratory, Kirtland AFB, NM 87117 (telephone: 505-853-6516, e-mail: kenneth.bole.2@us.af.mil).

H Bradley was with Air Force Research Laboratory, Kirtland AFB, NM 87117.



Fig. 1: GaN HEMT structure. Figure adapted from [1].

TABLE I

COMMERCIAL HEMT DEVICE CHARACTERISTICS

\begin{tabular}{llll} 
Vendor & Rated Power & Test Frequency & Facility \\
\hline A & $30 \mathrm{~W}$ & DC, $2.14 \mathrm{GHz}$ & LBNL \\
A & $120 \mathrm{~W}$ & DC, $2.14 \mathrm{GHz}$ & LBNL \\
B & $100 \mathrm{~W}$ & DC, L1 & LBNL \\
C & $35 \mathrm{~W}$ & DC, $3.2 \mathrm{GHz}$ & LBNL \\
D & $25 \mathrm{~W}$ & DC, $3.5 \mathrm{GHz}$ & TAMU \\
\hline
\end{tabular}

\section{A. Lawrence Berkeley National Laboratory}

The testing conducted at the Lawrence Berkeley National Laboratory (LBNL) included a series of experiments developed to explore leakage currents and RF characteristics of multiple high- and low-power commercial devices. The tests used $5.8 \mathrm{MeV}$ neon $(\mathrm{Ne}), 38.96 \mathrm{MeV}$ krypton $(\mathrm{Kr})$, 53.03 MeV silver (Ag), and 58.78 MeV xenon (Xe). The tests involved a series of exposures to a fluence of $1 \times 107$ ions/cm2 under operational bias conditions. The irradiations are done in 1 milliTorr (mT) vacuum.

Testing was done to observe leakage in the device under test (DUT) during RF drive. A secondary outcome of this test was to capture transients generated by ions. RF measurements were performed with continuous wave carrier signals using the test setup and equipment shown in Fig. 2 and Table 2. Manufacturer demonstration boards were used to interface the amplifiers to the test equipment to ensure proper matching. Boards were attached to heat sinks and a cold plate to keep the amplifier baseplate at $22^{\circ} \mathrm{C}$ and manage thermal dissipation during test.

The remainder of the LBNL testing was done under DC conditions to further explore the conditions of the leakage current. The schematic for the DC test configuration is the same as used for the RF testing, as seen in Fig. 2. Again, manufacturer demonstration boards were used. 


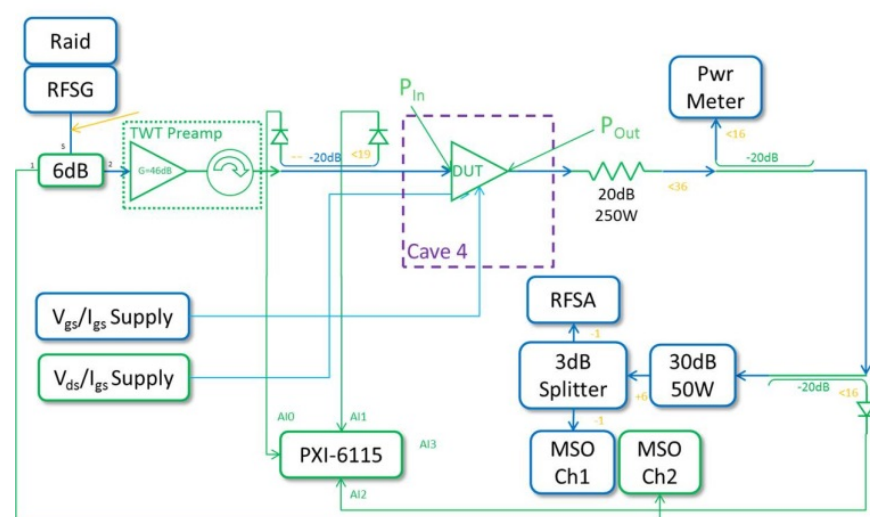

Fig. 2: RF test setup used for heavy-ion experiments at the LBNL facility Details of equipment used are listed in Table 2. "Cave 4" and the accompanying dotted line indicate the portion of the experiment that was in the test chamber at LBNL.

TABLE 2

TEST EQUIPMENT USED FOR RF HEAVY ION EXPERIMENTS SHOWN IN FIG. 2

\begin{tabular}{ll} 
Test Equipment & Model \\
\hline RF Signal Generator & 18 Slot NI PXIe 153869D- \\
RF Signal Analyzer & 01L \\
Pre-Amplifiers & Varian VZL69641K1 \\
& or Minicircuits TVA-11-422 \\
Power Meter & Minicircuits PWR-4RMS \\
(4x) Detectors (not shown) & (2) Agilent 423B, (1) Wiltron \\
& 75N50B, (1) Nardi 4503A \\
Oscilloscope & Tektronix MSO70404C \\
Gate Power Supply & Keithley 2200-72-1 \\
Drain Power Supply & BK Precision XLM10014 \\
\hline
\end{tabular}

\section{B. Texas $A \& M$}

The testing conducted at Texas A\&M University (TAMU) includes a series of experiments developed to explore leakage issues identified during a previous experiment at the same facility [5]. The tests primarily use $2955 \mathrm{MeV}$ gold ( $\mathrm{Au}$ ), but also $2715 \mathrm{MeV}$ tantalum (Ta), $2475 \mathrm{MeV}$ holmium (Ho), $2115 \mathrm{MeV}$ praseodymium (Pr), 1935 xenon (Xe), and 1635 silver $(\mathrm{Ag})$. The tests involve a series of exposures to a fluence of $2 \times 10^{7}$ ions $/ \mathrm{cm}^{2}$ under varying bias conditions. The irradiations are done in air.

As with the LBNL tests, testing was done to observe leakage in the DUT during RF drive. A secondary outcome of this test was to capture transients generated by ions. RF measurements were performed with a continuous wave $3.5 \mathrm{GHz}$ carrier signal using the test setup and equipment shown in Fig. 3 and Table 3. The manufacturer's demonstration board was used to interface the amplifiers to the test equipment to ensure proper matching. The board was attached to a heat sink to manage thermal dissipation during test.

Prior to irradiation, DC drift measurements were taken with the Vendor $\mathrm{D}$ device in pinch-off $(\mathrm{Vg}=-4.5 \mathrm{~V}$ and $\mathrm{VD}=28 \mathrm{~V})$ for 45 minutes. The unirradiated drift is minimal $(\sim 10 \mu \mathrm{A})$ compared to the leakage currents generated during irradiation $(\sim 100$ s of $\mu \mathrm{A})$.
The remainder of the TAMU testing was done under DC conditions to further explore the conditions of the leakage current. A schematic for the DC test configuration is shown in Fig. 4. Again, the manufacturer's demonstration board was used for the device fixture.

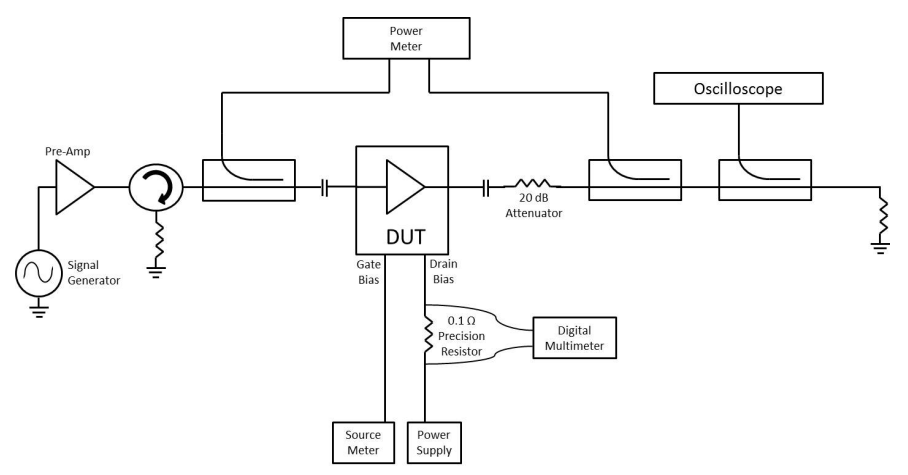

Fig. 3: RF test setup used for heavy-ion experiments at the TAMU facility. Details of equipment used are listed in Table 3.

TABLE 3

TEST EQUIPMENT USED FOR RF HEAVY ION EXPERIMENTS SHOWN IN FIG. 3

\begin{tabular}{ll} 
Test Equipment & Model \\
\hline Signal Generator & HP 83623B \\
Pre-Amplifier & Ophir 5162 \\
Power Meter & HP EPM-442A \\
(2x) Power Sensors (not shown) & (2x) HP ECP-E26A \\
Oscilloscope & Tektronix MSO72004C \\
Source Meter & Keithley 2410 \\
Power Supply & TDK Lambda Gen150-10 \\
Digital Multimeter & HP 3458A \\
\hline
\end{tabular}

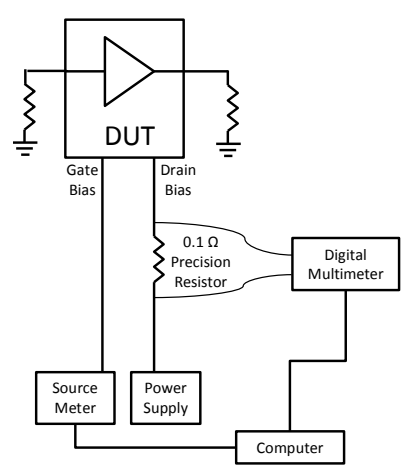

Fig. 4: DC test setup for TAMU testing.

\section{EXPERIMENTAL RESULTS}

During the RF tests, previously unirradiated $100 \mathrm{~W}+$ and 25 $35 \mathrm{~W}$ rated devices from 4 commercial manufacturers were biased at their recommended (pre-radiation) quiescent conditions as shown in Table 4. The devices were operated at frequencies of $1.57542,2.14,3.2$, and $3.5 \mathrm{GHz}$ with varying levels of RF power output.

At LBNL, parts were exposed up to six times to a fluence of $1.0 \times 10^{7}$ ions $/ \mathrm{cm}^{2}$ each time (once each to $\mathrm{Ne}, \mathrm{Kr}$, and $\mathrm{Ag}$, and up to three times to $\mathrm{Xe}$ ). At TAMU, the devices were subjected to $\mathrm{Au}$ exposures five times successively to a fluence of $2.0 \times 10^{7}$ ions $/ \mathrm{cm}^{2}$ each. 
Operating characteristics were monitored prior to, during and after each exposure. This time between exposures (typically $<60 \mathrm{~s}$ ) has been removed from each dataset. No efforts were taking during exposures to maintain the manufacturer's recommended quiescent currents. That is, the drain current is allowed to change with exposure to radiation.

TABLE 4

DC CONDITIONS OF DEVICES USED FOR RF HEAVY ION EXPERIMENTS

\begin{tabular}{lllll} 
Vendor & $\mathrm{I}_{\mathrm{DS}}$ & $\mathrm{V}_{\mathrm{DS}}$ & $\mathrm{V}_{\mathrm{GS}}$ & Peak Power \\
\hline $\mathrm{A}$ & $130 \mathrm{~mA}$ & $28 \mathrm{~V}$ & $-3.0 \mathrm{~V}$ & $36.4 \mathrm{dBm}$ \\
$\mathrm{A}$ & $440 \mathrm{~mA}$ & $48 \mathrm{~V}$ & $-2.9 \mathrm{~V}$ & $38.8 \mathrm{dBm}$ \\
$\mathrm{B}$ & $500 \mathrm{~mA}$ & $50 \mathrm{~V}$ & $-2.6 \mathrm{~V}$ & $49.5 \mathrm{dBm}$ \\
$\mathrm{C}$ & $500 \mathrm{~mA}$ & $28 \mathrm{~V}$ & $-2.4 \mathrm{~V}$ & $42.5 \mathrm{dBm}$ \\
$\mathrm{D}$ & $250 \mathrm{~mA}$ & $28 \mathrm{~V}$ & $-2.5 \mathrm{~V}$ & $40.0 \mathrm{dBm}$ \\
\hline
\end{tabular}

\section{A. Gate Current Results}

Figures 5-10 show gate current results with respect to accumulated exposure time. In general gate current increased during exposures for the devices with varying levels of annealing. Figures 6 and 7 show results for two previously unirradiated devices from Vendor B, described as "DUT1" and "DUT2". These devices exhibit significantly different annealing responses. These differences could be due to variability in the manufacturing process, but additional testing is needed to draw significant conclusions. The gate current responses for the low power devices from Vendors A and $\mathrm{C}$ are shown in Figs. 8 and 9, respectively.

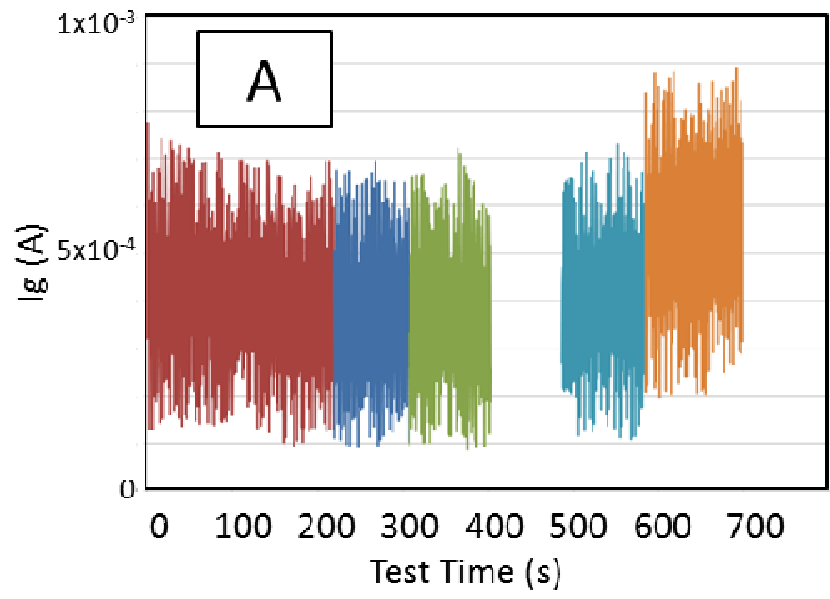

Figure 5: Gate current remains approximately constant during exposures for Vendor A high-power device. Exposures are, from left to right, $\mathrm{Ne}, \mathrm{Kr}, \mathrm{Ag}$, $<$ gap $>, \mathrm{Xe} 2$, and $\mathrm{Xe}_{3}$. The gap in data is for a run, $\mathrm{Xe}_{1}$ in which data was not recorded for this device. The $\mathrm{Xe}_{3}$ data are taken with bias conditions intended to observe any high-power effects.



Figure 6: Gate current increases during exposures with minimal recovery for Vendor B's DUT1 high-power device. Exposures are, from left to right, $\mathrm{Ne}$, $\mathrm{Kr}, \mathrm{Ag}, \mathrm{Xe} 1, \mathrm{Xe} 2$, and $\mathrm{Xe} 3$

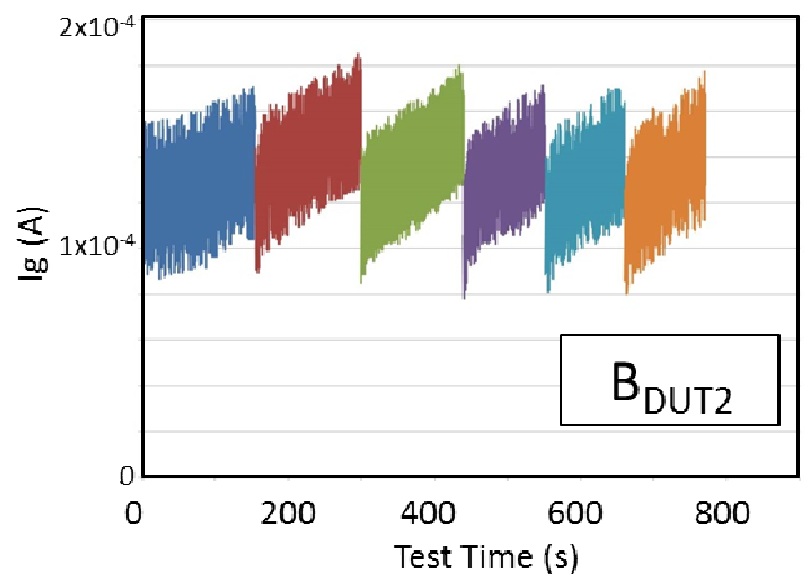

Figure 7: Gate current increases during exposures with near full recovery for DUT2 from Vendor B. Exposures are, from left to right, $\mathrm{Ne}, \mathrm{Kr}, \mathrm{Ag}, \mathrm{Xe}_{1}$, $\mathrm{Xe} 2$, and $\mathrm{Xe}_{3}$.



Figure 8: Gate current increases with higher LET exposure with minimal annealing for Vendor A low power device. Exposures are, from left to right, $\mathrm{Ne}, \mathrm{Ag}, \mathrm{Xe} 2$, and $\mathrm{Xe}_{3}$. 


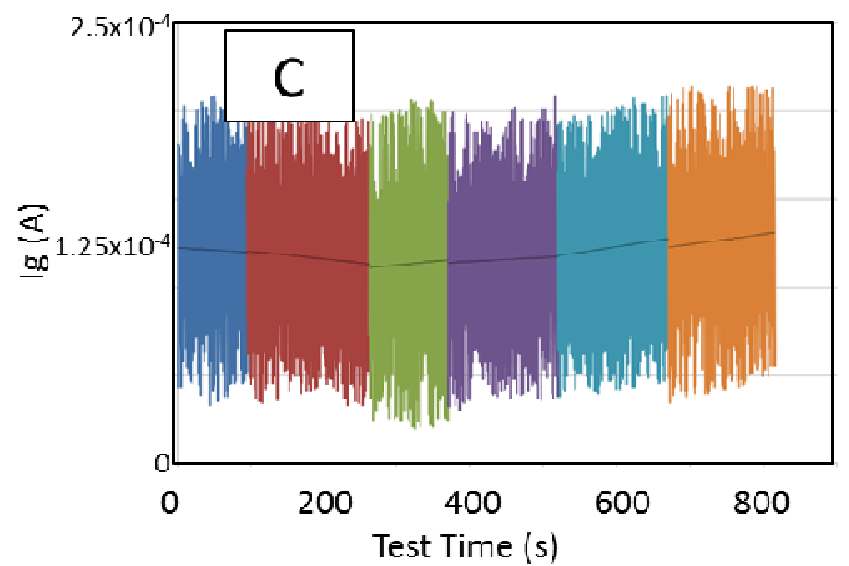

Figure 9: Gate current stays the same with each exposure for high power Vendor $\mathrm{C}$ device. Exposures are, from left to right, $\mathrm{Ne}, \mathrm{Kr}, \mathrm{Ag}, \mathrm{Xe}_{1}, \mathrm{Xe} 2$, and $\mathrm{Xe}_{3}$.

In order to observe changes in leakage currents across repeated heavy ion exposures, two Vendor D DUTs were irradiated with gold in ten successive exposures to fluences up to $2 \times 10^{7}$ atoms $/ \mathrm{cm}^{2}$ with a 5 minute rest period following each irradiation. The devices were biased in pinch-off $(\mathrm{Vg}=-5 \mathrm{~V}$ and $\mathrm{Vd}=28 \mathrm{~V})$ during both irradiation and rest periods. Gate and drain current sweeps were done before each irradiation and at the conclusion of the experiment. A single data point $\left(\mathrm{V}_{\mathrm{G}}=-4.9 \mathrm{~V}, \mathrm{~V}_{\mathrm{D}}=28 \mathrm{~V}\right)$ is recorded from each current sweep and plotted in Figure 11 with respect to the accumulated fluence of the devices. In this figure, solid icons represent data from $\mathrm{S} / \mathrm{N} 5$; unfilled icons represent data from $\mathrm{S} / \mathrm{N} 6$ from Vendor D. This data point was chosen because it was the lowest gate bias in which a complete data set was available for each DUT.

Results for drain current testing are not shown in this paper. The trends for drain current closely follow the patterns of the saturated power results shown in the following section.

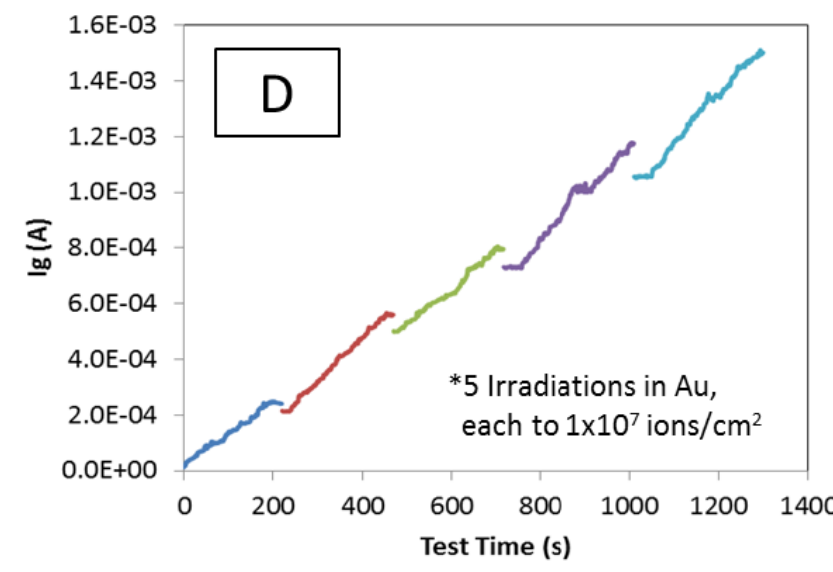

Figure 10: Gate current magnitude increases with each exposure with minimal annealing. Breaks indicate separate exposures to $\mathrm{Au}$. Each exposure is to a fluence of $2.0 \times 10^{7} \mathrm{ions} / \mathrm{cm}^{2}$.

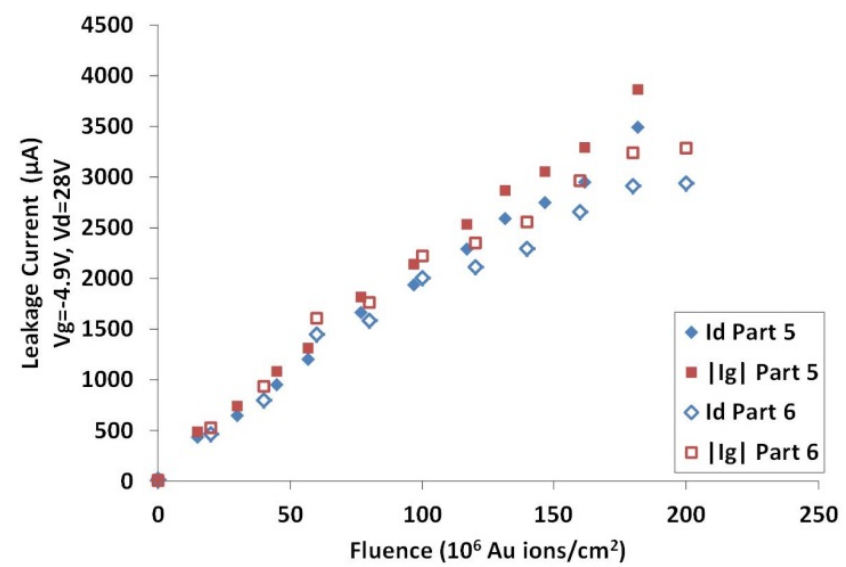

Figure 11: The magnitude of gate and drain leakage currents of the Vendor D device type at gate voltage $-4.9 \mathrm{~V}$ and drain voltage $28 \mathrm{~V}$ before each irradiation and at the conclusion of the test.

\section{B. Power Saturation Results}

During this series of exposures, $\mathrm{P}_{\mathrm{SAT}}$ slightly decreased during runs, with some annealing between runs (see Figures 12-15). Since there appear to be no major decreases in $\mathrm{P}_{\mathrm{SAT}}$, this can be explained by increases in the junction temperature while the devices warm up. As can be seen in the experimental setup section for LBNL above, we also were able to record RF output transients. Note that the $\mathrm{Xe}_{3}$ data in Figure 12 is inconsistent with the general trend of the rest of the data. This is due to a tweak to the test setup to test the device in a power-stressed condition.

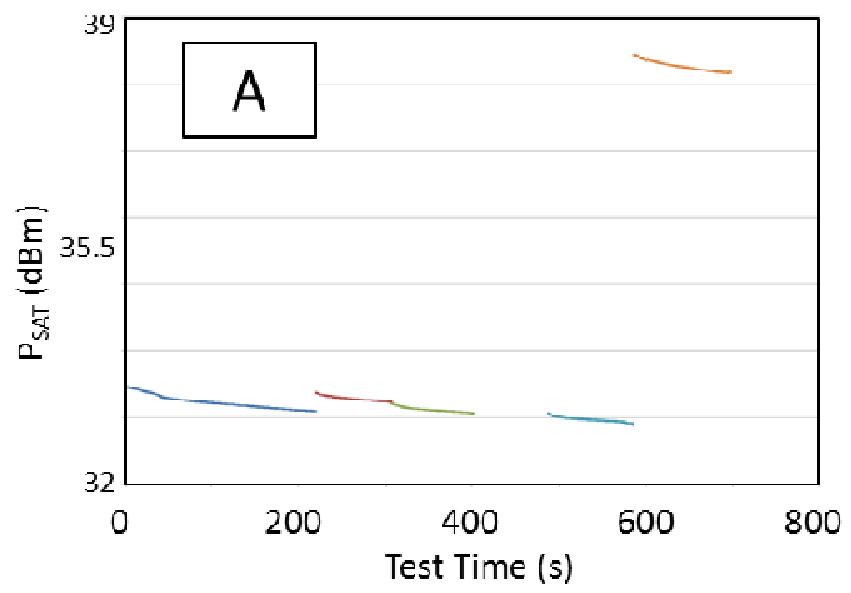

Figure 12: $R F$ P $\mathrm{P}_{\mathrm{SAT}}$ current decreases during exposures with minimal recovery for Vendor A high-power device. . Exposures are, from left to right, $\mathrm{Ne}, \mathrm{Kr}, \mathrm{Ag},<\mathrm{gap}>, \mathrm{Xe} 2$, and $\mathrm{Xe}_{3} .$. The gap in data is for a run, $\mathrm{Xe}_{1}$ in which data was not recorded for this device. The $\mathrm{Xe}_{3}$ data are taken with bias conditions intended to observe any high-power effects.

During this series of exposures for Vendor D, no changes in $\mathrm{P}_{\mathrm{SAT}}$ were observed. As mentioned in the experimental setup section above, there was an attempt to trigger on RF output transients, but with no success. This could be due to the matching network, or simply because there were no transients during test. The frequency spectrum was measured for the final three exposures, but no anomalous behavior was observed. 




Figure 13: $R F \mathrm{P}_{\mathrm{SAT}}$ current decreases during exposures with minimal recovery for Vendor B (DUT1) high-power device. Exposures are, from left to right, $\mathrm{Ne}, \mathrm{Kr}, \mathrm{Ag}, \mathrm{Xe}_{1}, \mathrm{Xe} 2$, and $\mathrm{Xe}_{3}$.

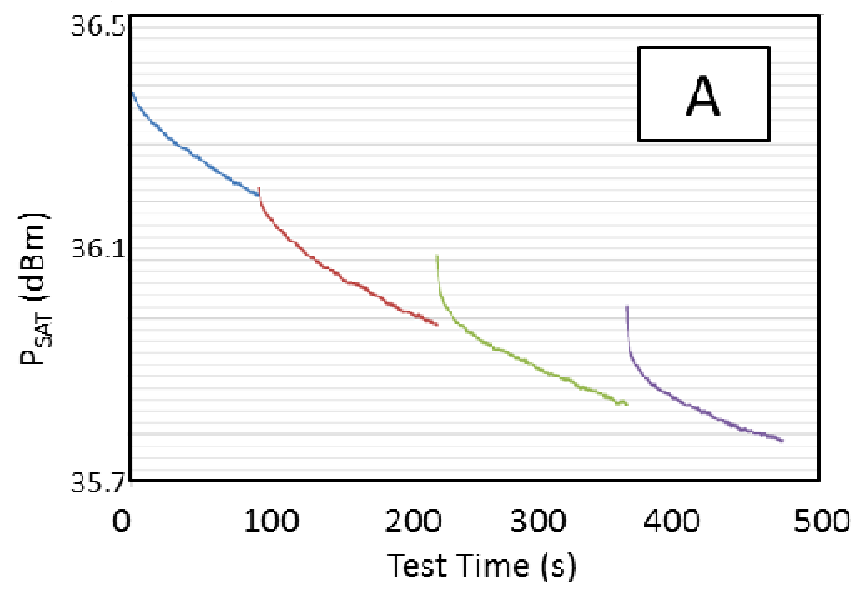

Figure 14: RF $\mathrm{P}_{\mathrm{SAT}}$ current decreases during with minimal recovery for Vendor A low-power device. Exposures are, from left to right, $\mathrm{Ne}, \mathrm{Ag}, \mathrm{Xe}$, and $\mathrm{Xe}_{3}$.

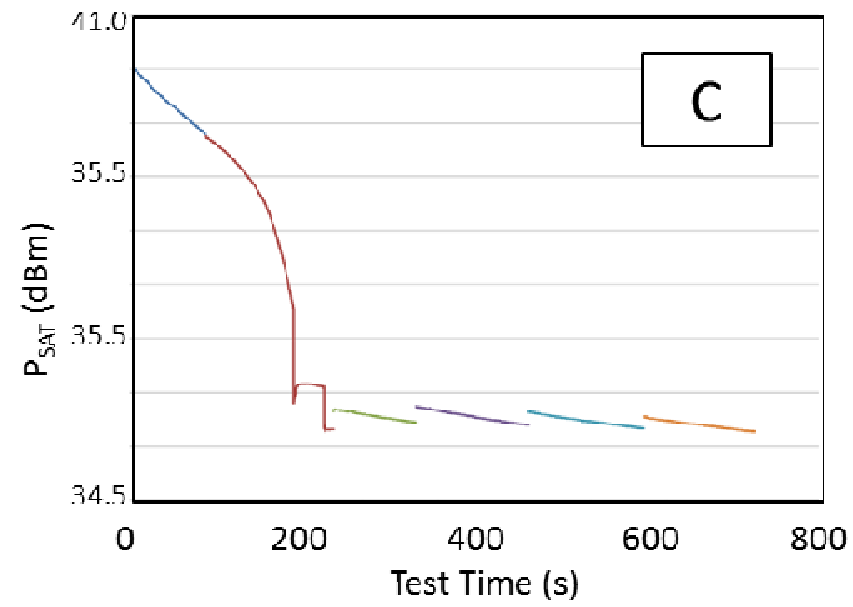

Figure 15: $\mathrm{RF} \mathrm{P}_{\mathrm{SAT}}$ current decreases during exposures with minimal recovery for Vendor $\mathrm{C}$ low-power device. Exposures are, from left to right, $\mathrm{Ne}, \mathrm{Kr}, \mathrm{Ag}, \mathrm{Xe}_{1}, \mathrm{Xe} 2$, and $\mathrm{Xe}_{3}$.

\section{DISCUSSION}

It is clear that degradation of leakage current is a concern for these devices. However, the magnitude of the leakage degradation depends on the vendor. For example, the highpower device type from Vender A showed little degradation, while DUTs from Vendor D show significant degradation. This difference could be due to differences in facilities, ion energies, ion weights, test conditions, burn-in status, or several other factors.

High-power Vendor B DUTs were not consistent in response under identical test conditions, with one showing little annealing (Fig. 7) and the other showing significant annealing (Fig. 8). This implies that the manufacturing process may not be stable.

Some conclusions can be drawn based on these data. First, the leakage current increases with the weight of the incident ion (see Appendix A for a note on LET and stopping power in $\mathrm{GaN})$. Second, leakage current varies from vendor-tovendor and DUT-to-DUT. This implies that vendors must be carefully evaluated for process maturity and suitability for the intended application.

In conclusion, these studies emphasize the need for consistent test processes for analysis of devices. Small variations in test setups, particularly in the RF spectrum make large differences in test results. There is a need to standardize test procedures in the radiation effects community.

\section{APPENDIX A}

The following is a brief discussion on the interaction of heavy ions with GaN to set the theoretical expectation of energy transfer and deposition. The passage of the heavy ion through the DUT material produces ionization which is related to the energy deposition per unit track length. There are two commonly used measures of this energy deposition: stopping power and LET. Stopping power is simply the energy deposition per unit track length in convenient units of $\mathrm{MeV} / \mathrm{um}$. Linear energy transfer (LET) is the stopping power normalized to the density of the DUT target material. LET has convenient units of $\mathrm{MeV} / \mathrm{mg} / \mathrm{cm}^{2}$.

The measure of the amount of ionization produced by heavy ion tracks is the number of electron-hole pairs produced in the material per unit volume. These extra electron-hole pairs can be collected as extra current or as charge on the node of a capacitor. Other heavy ion effects include the disruption of the bonding of atoms at material interfaces, the production of dangling bonds. These interface states can become leakage paths.

Heavy ion testing of devices and circuits is performed for basic physics research and also for assessing the suitability of the components for a particular application environment, perhaps a space environment such as earth orbit or interplanetary mission. The parameters in the test matrix include the DUT electrical inputs and the parameters of the beam. Beam parameters include ion mass and ion energy and ion angle of incidence. Reference [6] has a broad scope of tutorial material and references regarding the setup and 
performance of heavy ion experiments for hardness assurance testing.

For a particular DUT target material and a particular heavy ion beam, the energy deposition per unit length in the material is ion energy-dependent. Figure A1 below shows the energy dependence of the LET for the ions used in this study. The maximum LET occurs for a particular target material and ion at an energy called the "Bragg peak." A given LET in the material can be achieved for the same ion with two different energies, one above and one below the Bragg peak.



Figure A1: LET vs. ion energy for ions on a GaN target material.

Except for very specialized applications, the energy of the ion should be chosen to be above the Bragg peak. For ion energies much below the Bragg peak, the ion track starts becoming non-straight-line, described statistically as "straggling." The straight line ion paths are optimum because a straight line ion path allows for uniform distribution of energy per unit volume in the material. When there is significant straggling, the energy deposition in the DUT becomes non-uniform. Interpreting test results and comparing data among different experiments becomes difficult when the energy deposition is non-uniform. Another reason to avoid using beam energies below the Bragg peak is that the experiment becomes more sensitive to the details of the thickness and composition of the device overlayers, such as tungsten vias and gold field plates. These high- $Z$ materials introduce much uncertainty in the beam properties because of straggling. The straggling might possibly make the results vendor-dependent in a way that the experimenter did not intend, if the different vendors use different materials as overlayers. Such is the case for the $5.8 \mathrm{MeV}$ beam of $20-\mathrm{Ne}$ ions in this test matrix. The Ne ion energy is low enough that straggling dominates and the true flux and LET on the active layer are not well defined. Therefore, while some effect is seen with the neon ion irradiation, the results should be interpreted with this note in mind.

\section{ACKNOWLEDGMENT}

The authors would like to thank their GaN Tech collaborators at JPL, NRL, AFRL/RX, AFRL/RY, the High Reliability Electronics Virtual Center (HiREV), Aerospace Corp. and Vanderbilt for their inputs into the testing of these devices.

\section{REFERENCES}

[1] M. Rostewitz, K. Hirche, J. Latti, E. Jutzi, "Single Event Effect Analysis on DC and RF Operated AlGaN/GaN HEMTs," IEEE Trans. Nucl. Sci., vol. 60, no. 4, pp. 2525 - 2529, Aug. 2013.

[2] R. D. Harris, L. Z. Schieck, J. P. Hoffman, T. Thrivikraman, M.Jenabi, Y. Gim, and T. Miyahira, "Radiation characterization of commercial GaN devices," Radiation Effects Data Workshop (REDW) in conjunction with the 2011 Nuclear Science and Radiation Technology Conference, pp. 177-181, Las Vegas, NV, 2011.

[3] S. Bazzoli, S. Girard, V. Ferlet-Cavrois, J. Baggio, P. Paillet, and O. Duhamel, "SEE sensitivity of a COTS GaN transistor and silicon MOSFETs," Proc. 9th Eur. Conf. Radiation and Its Effects on Components and Systems (RADECS), pp. 1 - 5, Deauville, France, Sept. 10-14, 2007.

[4] S. Kuboyama, A. Maru, H. Shindou, N. Ikeda, T. Hirao, H. Abe, T. Tamura, "Single-Event Damages Caused by Heavy Ions Observed in AlGaN/GaN HEMTs," IEEE Trans. Nucl. Sci., vol. 58, no. 6, pp. 2734 -2738 , Dec. 2011.

[5] B. D. Olson, J. D. Ingalls, C. H. Rice, C. C. Hedge, P. L. Cole, A. R. Duncan, and S. E. Armstrong, "Leakage Current Degradation of Gallium Nitride Transistors Due to Heavy Ion Tests," Submitted to the Radiation Effects Data Workshop (REDW) in conjunction with the 2015 Nuclear Science and Radiation Technology Conference, Boston, MA, 2015

[6] J. Schwank, M. Shaneyfelt, and P. Dodd, "Radiation Hardness Assurance Testing of Microelectronic Devices and Integrated Circuits: Test Guideline for Proton and Heavy Ion Single-Event Effects," IEEE Trans. Nucl. Sci. 60 (2013) 2011. 